\title{
Rhetorical Categories and Linguistic Mechanisms in Describing Research Conditions: A Comparative Genre-Based Investigation into Researchers' Choices in Education and Applied Linguistics
}

\author{
Jason Miin-Hwa Lim*
}

\author{
Centre for the Promotion of Knowledge and Language Learning, Malaysian University of Sabah, Malaysia
}

\begin{abstract}
Novice writers of research reports often assume that research methods are generally not mentioned in the Results section of a research paper. The extent to which such an assumption is well-founded can be determined by conducting a mixed-method genre-based study of data obtained from authentic research papers. Using both quantitative and qualitative techniques in a genre analysis of two corpora of Results sections in linguistic and educational research articles, the researcher has investigated the various ways in which research methods are mentioned or reiterated in the Results sections of research reports. The findings have shown that despite the significantly different frequencies of steps related to data collection procedures in the two disciplines, research methods are frequently incorporated in the Results section. What merits attention, however, is an important range of communicative functions and an interesting repertoire of linguistic choices that should be thoroughly studied in the preparation of teaching material aimed at enlightening learners on how research methods need to be described in presenting results. The findings of this study will demonstrate that teaching novice writers how to describe research methods while presenting certain results should in fact constitute an important component in an ESP programme intended to promote academic literacy.
\end{abstract}

Keywords: English for specific purposes, communicative functions, genre analysis, second language acquisition, discourse analysis, educational linguistics, dissertation writing, educational and linguistic research.

\section{INTRODUCTION}

Teaching second language learners to prepare a wellwritten research report can be a challenging task, especially when it comes to the writing of the Results section, which is often the section that presents new findings of a study being reported. While much research has been conducted on the writing of the Introduction section [1-3], the generic structure of the Results section [4-6] and that of the Discussion/Conclusion section [7, 8], a detailed study that focuses on some essential and yet neglected aspects of the Results section has yet to be carried out. One of these aspects which form a dearth in past research has to do with the interdisciplinary and inter-procedural differences (i.e., differences between articles using different research procedures) in the occurrences of certain communicative functions, particularly 'describing research conditions'. These rhetorical functions are important in ESP courses offered at tertiary level and need to be studied in sufficient detail in our attempt to develop learners' academic literacy.

'Describing research conditions' is generally understood as a reiteration or description of the research methods or procedures employed in obtaining research results. In this text segment, writers of articles refer to some research procedures which are usually described in the preceding Method/s section while presenting their findings in the Results section. Although it is not surprising that research procedures are usually delineated in the Method/s section of a research

*Address correspondence to this author at the Centre for the Promotion of Knowledge and Language Learning, Malaysian University of Sabah, Malaysia; E-mail: drjasonlim@gmail.com report, their occurrences in the Results section can at times be disputed. In some teaching materials intended for novice writers of research reports, scant attention has been paid to the description of research procedures in the Results section. Weissberg and Buker [9], for example, presented only three basic elements of information in the Results section of a research report, which are (i) statements that locate the figures where results can be found, (ii) those which present the most important findings, and (iii) other statements commenting on the results. Only in an exercise that required an identification of information elements did they instruct learners to find out a type of information, namely 'research procedure', which was not listed as one of the main types of information in the Results section.

Similarly, Nwogu [10] considers 'indicating consistent observations' and 'indicating inconsistent observations' as two major rhetorical moves in medical Results sections without highlighting the significance of research procedures in the presentation of results. The lack of emphasis on the description of research methods or procedures is questionable because other studies [4-6, 11] have considered research procedure/s as an important rhetorical category in the Results section. To a certain extent, it may be argued that the identification of research procedure/s as a communicative function might partly be due to the fact that some researchers $[5,11]$ adopted Brett's [4] model and viewed a 'procedural (step)' as a 'presentation category' in their corpora of computing and medical research results. However, Lim's [6] study of management research results has shown that 'describing research conditions' is a pivotal category given that it can be found in all the management articles in his corpus. 
Even though it is a general phenomenon that research methods, which are usually mentioned in the Method section of a management research report, can be reiterated in the Results section, we are uncertain as to whether the same phenomenon is prevalent in some fields, such as the teaching of English as a second language (TESL), an area of interest for a considerably large number of undergraduate and postgraduate students in the university where the researcher is teaching. As TESL research papers are often published in research journals associated with either applied linguistics or education, it is necessary for TESL researchers to be aware of the conditions and requirements expected by the two related discourse communities.

Given the rationale for studying the Results sections in these two inter-related fields, this paper focuses on one major communicative function, namely 'describing research conditions' and will attempt to identify the constituent steps involved in this major rhetorical function. A detailed analysis of the linguistic resources used in each of these steps has been conducted to demonstrate how writers in applied linguistics and education fulfil the need to describe research conditions in the reporting of results.

Given the scope for this study, three research questions pertaining to the purpose of this study have been formulated as follows:

1. What are the rhetorical steps used in describing research conditions in the Results sections of research reports in applied linguistics and education?

2. Are there any significant inter-disciplinary and interprocedural differences in the frequencies of the rhetorical steps of 'describing research conditions' in linguistic and educational Results sections written based on quantitative, qualitative and mixed-method research procedures? (Note: The term 'linguistic Results sections' in this paper refers to those in the discipline of applied linguistics and not theoretical linguistics.)

3. What are the linguistic resources used in each of the rhetorical steps in 'describing research conditions'?

On the basis of these three research questions, attempts will be made to discuss the results by focusing on the linkage between the functions of the steps and the linguistic resources used to fulfil them. Subsequently, the pedagogical relevance of studying these steps in 'describing research conditions' will be discussed in the final section of this paper.

\section{RESEARCH PROCEDURES}

\section{Sampling Procedure}

On the basis of the research questions, the sampling procedure used in this study will be described. In this mixedmethod study that focuses on the description of research conditions in the presentation of findings, a total of 30 Results sections were obtained from six established international refereed journals. While 15 Results sections (i.e. RSs 1 through 15) were extracted from three high-status linguistic journals, namely TESOL Quarterly, English for Specific Purposes and Applied Linguistics, the remaining 15 RSs (i.e. RSs 16 through 30) were taken from reputed educa- tional journals, which are Educational Research, International Journal of Educational Research and Studies in Educational Evaluation. This means that five articles were obtained from each of the six international refereed journals. The selection of 30 articles is considered adequate for a detailed analysis in that the focus of the present study is on investigating relationships between linguistic resources and rhetorical functions of describing research conditions, rather than merely a statistical count of linguistic features or a quantitative record of the frequencies of individual steps. All the research articles were chosen using the guiding principle that each article should contain all the four major sections, which are the Introduction, Method/s, Results and Discussion sections. Using this principle of selection is essential in that this study focuses on the description of research conditions in the Results section instead of other sections. Hence, articles that do not consist of one of the four sections, such as the Method section, were not included in the selection.

Certain principles underlying the collection of data were observed in an attempt to (i) avoid biases in the selection procedure, and (ii) provide adequate data in the sample to be analysed. The sources and texts were systematically selected to ensure a representative sample of the language used by members of the academic profession. Articles from the journals were chosen in a purposive manner by considering the subfields in which they could be placed. To be specific, no more than one article was selected from each issue, and no more than two articles related to the same subject area were selected in the ten issues in each discipline. The two corpora consisted of 30 research articles $(\mathrm{N}=30)$ contain the same number of linguistic research reports $\left(\mathrm{N}_{\mathrm{L}}=15\right)$ and educational research reports $\left(\mathrm{N}_{\mathrm{E}}=15\right)$, with five articles representing each of the six journals concerned. The papers in each discipline were selected to ensure that the subject matter covered by the articles would exhibit a wide range of topic areas and linguistic choices. Two quantitative research reports, two qualitative papers, and one mixed-method research report were chosen from each journal in order to reflect the existence of a prevalent range of research procedures in each discipline. One (instead of two) mixed-method articles from each journal was selected because papers that clearly exhibit a mixture of research procedures were comparatively rarer than those which were exclusively qualitative or mainly quantitative.

With respect to the research procedures used in the 30 research papers, the criteria employed in differentiating quantitative from qualitative studies were based on the major features of research designs discussed by Gay, Mills and Airasian [12] who have distinguished between (i) qualitative studies that adopt an inductive approach, focus on interpreting participants' perspectives, describe and explain relationships, allow a specific focus to emerge while the research progresses, and emphasise the purposeful selection of participants or samples based on researchers' articulateness and experience in the research circumstances, and (ii) quantitative research that uses an deductive approach, focus on objective reality which is to be discovered, establish causeeffect relationships, identify hypotheses to be tested, and stress selection of participants at random. Tables $\mathbf{1}$ through $\mathbf{3}$ provide an overview of the procedures and purposes. 
Table 1. Types, Purposes and Procedures of RSs 1 through 10 (Selected from TESOL Quarterly and English for Specific Purposes)

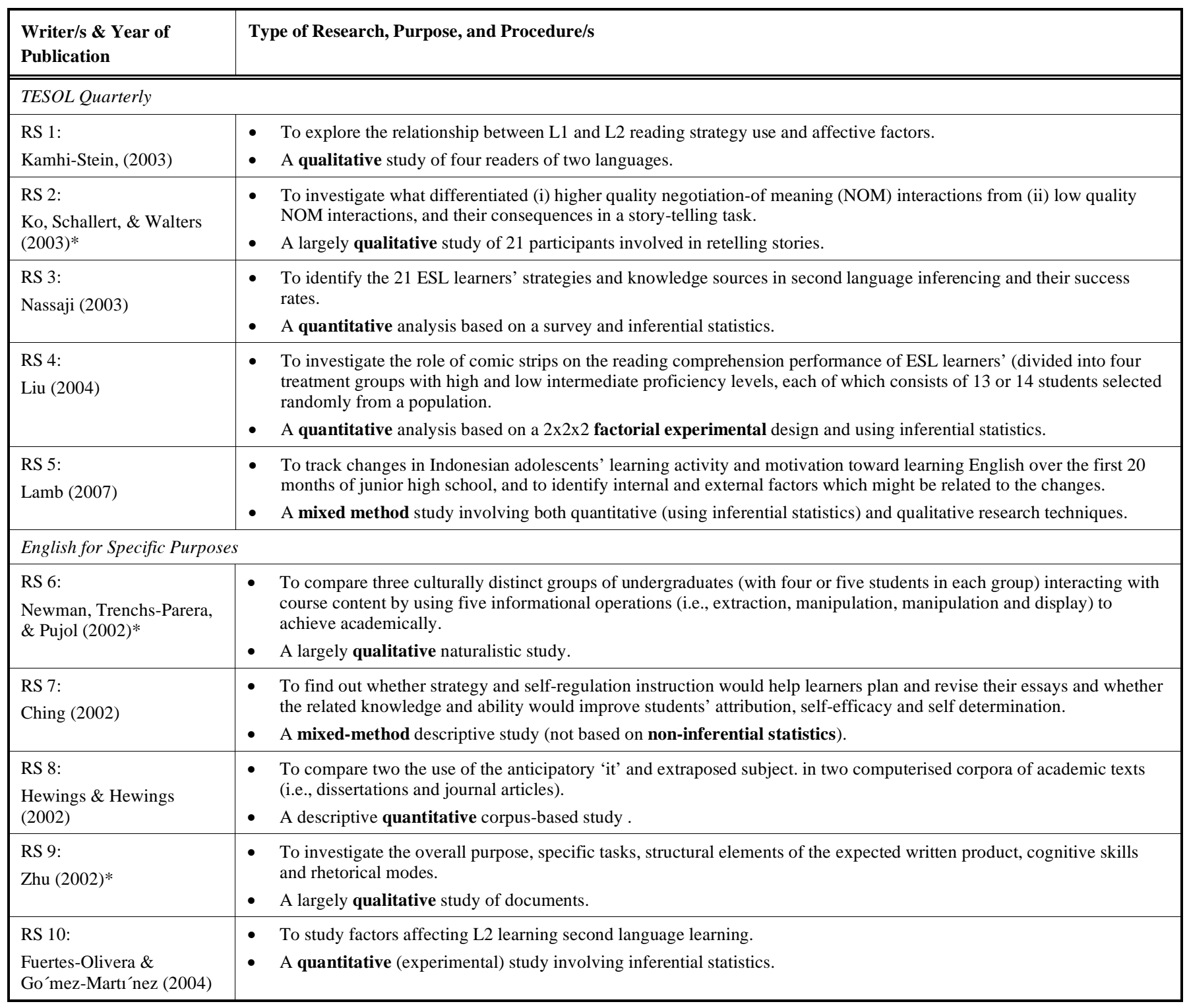

Table 2. Types, Purposes and Procedures of RSs 11 through 20 (Selected from Applied Linguistics and Educational Research)

\begin{tabular}{|c|c|}
\hline $\begin{array}{l}\text { Writer/s \& Year of } \\
\text { Publication }\end{array}$ & Type of Research, Purpose, and Procedure/s \\
\hline \multicolumn{2}{|l|}{ Applied Linguistics } \\
\hline $\begin{array}{l}\text { RS 11: } \\
\text { Reiter et al. (2005) }\end{array}$ & $\begin{array}{l}\text { - To investigate (i) whether requests (which are pragmatically equivalent) reflect the same degree of speaker certainty in the } \\
\text { likelihood of hearer compliance in English and Spanish, (ii) whether there is a relationship between the degrees of certainty } \\
\text { and the use/non-use of standard conventionally indirect requests, and (iii) whether there is a relationship between requester's } \\
\text { certainty levels and their internal mitigation of their requests. } \\
\text { - A mixed-method exploratory empirical study involving } 23 \text { Spaniards and } 32 \text { Britons aged 18-24. }\end{array}$ \\
\hline $\begin{array}{l}\text { RS 12: } \\
\text { Cekaite \& Aronsson } \\
(2005)\end{array}$ & $\begin{array}{l}\text { - To investigate the relationship between language play and language learning by focusing on children's language play in } \\
\text { spontaneous classroom conversations. } \\
\text { - A qualitative study of multiparty talk. }\end{array}$ \\
\hline $\begin{array}{l}\text { RS 13: } \\
\text { Ellis (2006) }\end{array}$ & $\begin{array}{l}\text { - To (i) determine whether there are grammatical structures that are easy in terms of implicit knowledge but difficult in terms of } \\
\text { explicit knowledge, and vice versa, and (ii) to investigate the extent to which implicit/explicit knowledge of specific grammati- } \\
\text { cal features and structures is related to general L2 proficiency. } \\
\text { - A quantitative (correlational) study of the differential contributions of implicit and explicit knowledge of } 220 \text { L2 learners. }\end{array}$ \\
\hline
\end{tabular}


(Table 2). Contd.....

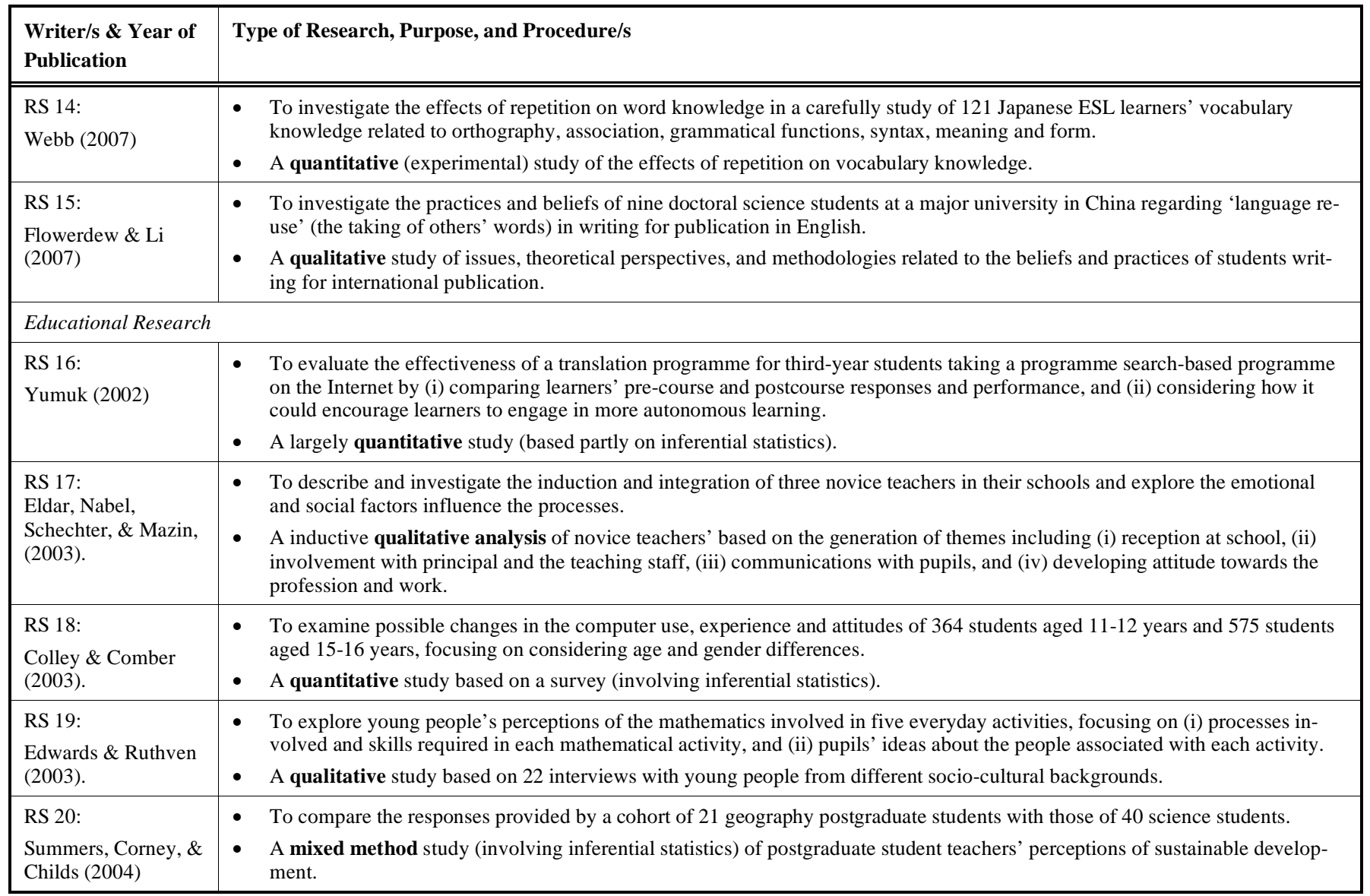

Table 3. Types, Purposes and Procedures of RSs 21 through 30 (Selected from International Journal of Educational Research and Studies in Educational Evaluation)

\begin{tabular}{|c|c|}
\hline $\begin{array}{l}\text { Writer/s \& Year } \\
\text { of Publication }\end{array}$ & Type of Research, Purpose, and Procedure/s \\
\hline \multicolumn{2}{|c|}{ International Journal of Educational Research } \\
\hline $\begin{array}{l}\text { RS } 21 \\
\text { Bouffard, Roy, \& } \\
\text { Vezeau (2005) }\end{array}$ & $\begin{array}{l}\text { - To (i) compare children's self-esteem, perceived competence, negative perfectionism and beliefs of peer acceptance, tempera- } \\
\text { ment-based factors, and socio-emotional adjustment of underachieving and non-achieving elementary school children, and (ii) de- } \\
\text { termine whether children's perceptions of parental support act as a protective factor promoting positive self self-perceptions and } \\
\text { socio-emotional adjustment. } \\
\text { - A quantitative (correlational) study of self-perceptions, temperament, socio-emotional adjustment and the perceptions of parental } \\
\text { support. }\end{array}$ \\
\hline $\begin{array}{l}\text { RS 22: } \\
\text { García-Sa'́nchez, } \\
\& \text { de Caso- } \\
\text { Fuertes (2005) }\end{array}$ & $\begin{array}{l}\text { - To compare the influence of three different writing programs (one which focused on writing strategies and skills, the second on } \\
\text { training writing strategies and reflexive practices, and the third on training writing skills using motivational strategies) to deter- } \\
\text { mine whether self-efficacy beliefs and attitudes towards writing (as constructs) could be more enhanced. } \\
\text { - A qualitative (experimental) study with three treatment groups involving } 1915^{\text {th }} \text { and } 6^{\text {th }} \text { grade students, aged } 10-13 \text {, with learning } \\
\text { disabilities and low achievement. }\end{array}$ \\
\hline $\begin{array}{l}\text { RS 23: } \\
\text { Lopez \& Allal } \\
(2007)\end{array}$ & $\begin{array}{l}\text { - To determine (i) how sociomathematical norms are constructed, and (ii) their role in a beneficial context where students (in two } \\
\text { third-grade classes, each of which has } 17 \text { students) are actively engaged in problem solving during whole-class discussions. } \\
\text { - A qualitative interpretative study of the sociomathematical norms and the regulation of problem solving. }\end{array}$ \\
\hline $\begin{array}{l}\text { RS 24: } \\
\text { Miell \& Littleton } \\
(2008)\end{array}$ & $\begin{array}{l}\text { - To explore the ways in which the band members collectively develop and evaluate their musical 'works in progress'. } \\
\text { - A qualitative study of a series of band rehearsals involving five young people preparing new songs and developing existing sets. }\end{array}$ \\
\hline $\begin{array}{l}\text { RS 25: } \\
\text { Ja“rvela“; } \\
\text { Ja“rvenoja, \& } \\
\text { Veermans (2008) }\end{array}$ & $\begin{array}{l}\text { - To examine (i) the kind of motivations and task-specific goals that individual students have in face-to face conditions }(\mathrm{n}=58) \text { and } \\
\text { virtual settings }(\mathrm{n}=41) \text {, and (ii) the ways in which they combined their motivations as a group in socially shared learning. } \\
\text { - A mixed-method experimental study (involving inferential statistics) of the dynamics of motivation in socially shared learning } \\
\text { from both individual and group practices. }\end{array}$ \\
\hline
\end{tabular}




\begin{tabular}{|c|c|}
\hline $\begin{array}{l}\text { Writer/s \& Year } \\
\text { of Publication }\end{array}$ & Type of Research, Purpose, and Procedure/s \\
\hline \multicolumn{2}{|c|}{ Studies in Educational Evaluation } \\
\hline $\begin{array}{l}\text { RS 26: } \\
\text { Gibton (2004) }\end{array}$ & $\begin{array}{l}\text { - To investigate how school principals' views on educational policy and law are organized into graphic mindscrapes, and how these } \\
\text { mindscrapes on educational policy and law and leadership are influenced by policy initiatives, policy and capacity tools, and law- } \\
\text { based educational policy reforms. } \\
\text { - A qualitative (experimental but not quantitative) study policy analysis. }\end{array}$ \\
\hline $\begin{array}{l}\text { RS 27: } \\
\text { Grammatiko- } \\
\text { poulos et al. } \\
(2005) \text {. }\end{array}$ & $\begin{array}{l}\text { - To evaluate the Olympic educational programme through interviews with } 55 \text { semi-structured interviews (which provided depths } \\
\text { through question probes that expand the respondents' responses) conducted with primary and secondary school principals se- } \\
\text { lected through analogical stratified sampling. } \\
\text { - A qualitative study of factors related to educational evaluation. }\end{array}$ \\
\hline $\begin{array}{l}\text { RS 28: } \\
\text { Orsmond et al. } \\
\text { (2006). }\end{array}$ & $\begin{array}{l}\text { - To (i) identify factors influencing } 33 \text { undergraduate students (who had constructed scientific posters) while approaching an as- } \\
\text { sessed assignment, and (ii) how these factors changed during the course of a biology poster assessment. } \\
\text { A mixed-method study of changes in the use of learning outcomes and distractions. }\end{array}$ \\
\hline $\begin{array}{l}\text { RS 29: } \\
\text { Gulikers et al. } \\
\text { (2006). }\end{array}$ & $\begin{array}{l}\text { - To investigate (i) the direct and indirect influences of students' perceptions of the authenticity of five assessment characteristics } \\
\text { on their study approach and learning outcomes, and (ii) the impact of perception of alignment between assessment and instruction } \\
\text { on the study approach and learning outcome. } \\
\text { - A quantitative study of the relations between student perceptions of assessment authenticity, and alignment of study approaches } \\
\text { and learning outcomes. }\end{array}$ \\
\hline $\begin{array}{l}\text { R30: } \\
\text { Hailikari et al. } \\
\text { (2007) }\end{array}$ & $\begin{array}{l}\text { - To (i) develop a prior knowledge assessment instrument that differentiates between various components of prior knowledge } \\
\text { which can be assessed by a range of assessment measures, and (ii) explore how prior knowledge is related to student achievement } \\
\text { in a university mathematics course. } \\
\text { - A quantitative exploratory investigation into ways of assessing prior knowledge, its components and their relation to student } \\
\text { achievement. }\end{array}$ \\
\hline
\end{tabular}

\section{Procedure for Rhetorical and Linguistic Analysis}

Using the corpora described above, the researcher studied the articles in terms of subsections, paragraphs, moves and steps, and attempts were first made to distinguish the various rhetorical moves in the texts concerned. Attention was focused on the linguistic characteristics of 'describing research conditions', which has been found to be a major rhetorical move in some previous studies on the Results sections in medical research reports [4, 5], computing RAs [11] and management papers [6].

To look into the descriptions of research conditions, attention was first focused on segments of the Results sections which were not associated with a direct presentation of findings. This was done to ensure that attempts could be made to identify whether research conditions were described in separate sentences and matrix clauses in such a way that the communicative function became a rhetorical move by itself. Functional and boundary indicators that were useful in dividing one communicative function from another were also employed to distinguish the descriptions of research methods from other rhetorical segments. More specifically, each Results section was chunked into smaller units with reference to (i) linguistic clues (used in texts to indicate internal boundaries), and (ii) more obvious markers like typographical features [13-15]. Subsequently, attention was directed to descriptions of research conditions in subordinate clauses, because such descriptions, if any, would generally be embedded in segments containing other communicative functions.

As the objective of this paper was on the descriptions of research conditions in the Results sections of linguistic and educational papers, only constituent steps connected with such descriptions would be explained and compared in terms of frequencies of occurrence. The two corpora were then compared using the Statistical Package for Social Sciences Version 16.0 with reference to the numbers of occurrences and central tendencies. The Mann-Whitney U-Tests were used to (i) conduct inter-disciplinary and quantitativequalitative comparisons in terms of the numbers of occurrences of each procedural step across disciplines. KruskalWallis H-tests were used to carry out inter-procedural comparisons (i.e., comparison of the frequencies of occurrences of each step in terms of the types of research procedures used, including quantitative, qualitative, and mixed-method research procedures). The two non-parametric tests were required because (i) the numbers of occurrences were not normally distributed in this study (as the normality in each case could be checked by referring to their respective histograms using SPSS [16]), (ii) the selection of the articles was purposeful rather than random in the present research, and (iii) the comparisons involved an independent nominal or categorical variable (i.e., discipline or type of procedure/s) and a dependent ratio variable (i.e., number of occurrences of each procedural step) which could have a true zero value [17-19].

After the rhetorical function of 'describing research conditions' had been identified, a linguistic analysis was carried out by considering the syntactic structures used repeatedly in the sample. Lexical choices employed to perform related or similar functions were also recorded and compared with one another in order to identify the regular patterns in lexical usage for describing research conditions. The analysis of the salient linguistic features was conducted with reference to the descriptions of English usage presented by Quirk, Greenbaum, Leech and Svartvik [20], Greenbaum and Quirk [21] and Lim [22, 23]. The linguistic analysis is essential in that it may provide useful information on the linguistic 
Table 4. Frequencies and Central Tendencies of Preparatory Steps in 'Describing Research Conditions' in the Results Sections of Linguistic and Educational Research Papers.

\begin{tabular}{|l|l|l|l|l|c|c|c|c|}
\hline Journal & $\begin{array}{l}\text { Article } \\
\text { no. }\end{array}$ & $\begin{array}{l}\text { Type of Re- } \\
\text { search Meth- } \\
\text { ods }\end{array}$ & $\begin{array}{l}\text { Heading for the } \\
\text { Results Section }\end{array}$ & $\begin{array}{c}\text { Step 1: } \\
\text { Relating Data Col- } \\
\text { lection Proce- } \\
\text { dure/s }\end{array}$ & $\begin{array}{c}\text { Sustifying Data } \\
\text { Collection } \\
\text { Procedure/s }\end{array}$ & $\begin{array}{c}\text { Step 3: } \\
\text { Recounting } \\
\text { Data Analy- } \\
\text { sis Proce- } \\
\text { dure/s }\end{array}$ & $\begin{array}{c}\text { Step 4: } \\
\text { Justifying } \\
\text { Data Analy- } \\
\text { sis Proce- } \\
\text { dure/s }\end{array}$ & $\begin{array}{c}\text { Steps } \\
1-4\end{array}$ \\
\hline \hline
\end{tabular}

Results sections (RSs) in Applied Linguistics

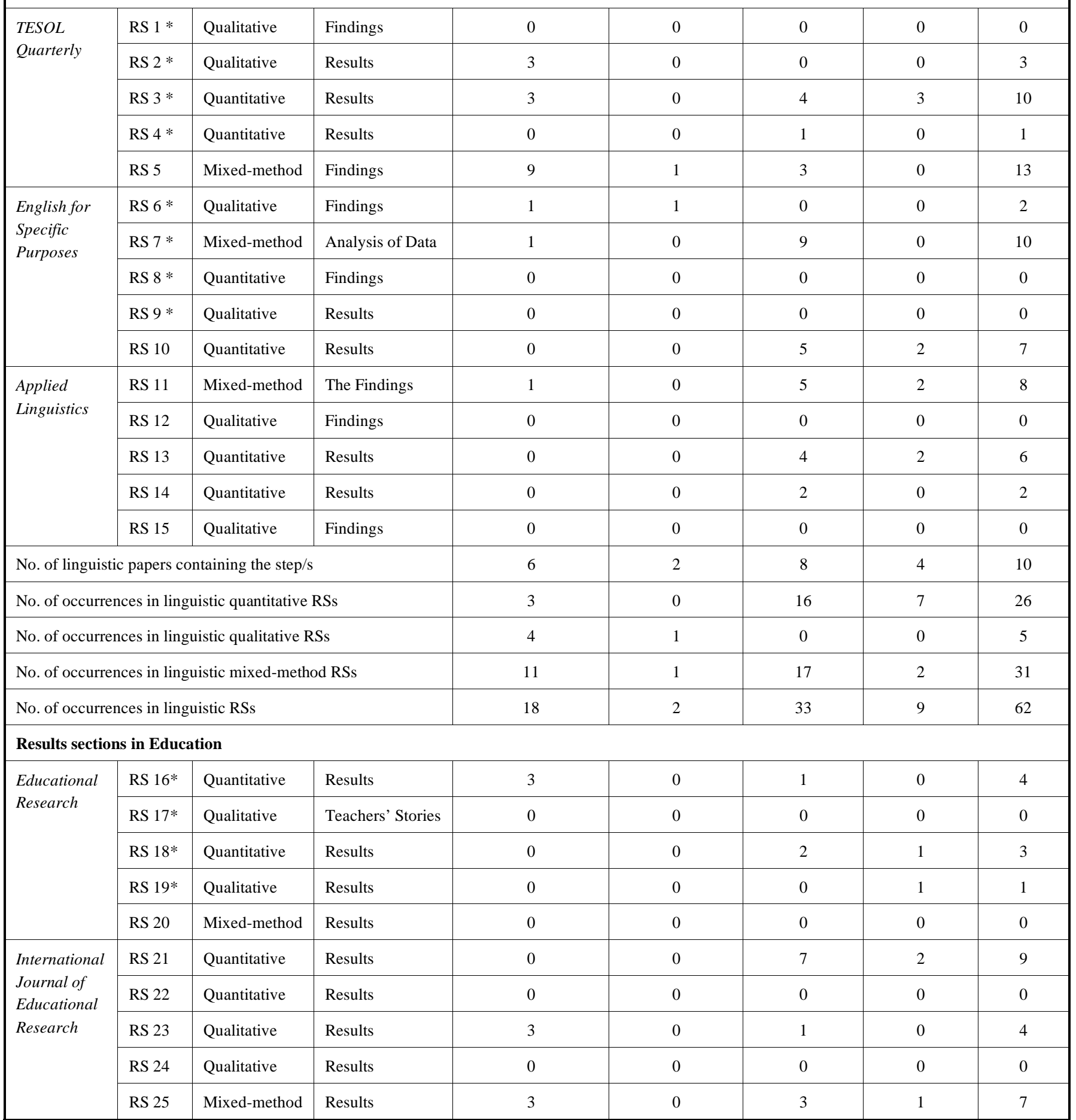


(Table 4). Contd.....

\begin{tabular}{|c|c|c|c|c|c|c|c|c|}
\hline Journal & $\begin{array}{l}\text { Article } \\
\text { no. }\end{array}$ & $\begin{array}{l}\text { Type of Re- } \\
\text { search Meth- } \\
\text { ods }\end{array}$ & $\begin{array}{l}\text { Heading for the } \\
\text { Results Section }\end{array}$ & $\begin{array}{c}\text { Step 1: } \\
\text { Relating Data Col- } \\
\text { lection Proce- } \\
\text { dure/s }\end{array}$ & $\begin{array}{c}\text { Step 2: } \\
\text { Justifying Data } \\
\text { Collection } \\
\text { Procedure/s }\end{array}$ & $\begin{array}{c}\text { Step 3: } \\
\text { Recounting } \\
\text { Data Analy- } \\
\text { sis Proce- } \\
\text { dure/s }\end{array}$ & $\begin{array}{c}\text { Step 4: } \\
\text { Justifying } \\
\text { Data Analy- } \\
\text { sis Proce- } \\
\text { dure/s }\end{array}$ & $\begin{array}{c}\text { Steps } \\
1-4\end{array}$ \\
\hline \multirow{4}{*}{$\begin{array}{l}\text { Studies in } \\
\text { Educational } \\
\text { Evaluation }\end{array}$} & RS 26 & Qualitative & Findings & 0 & 0 & 0 & 0 & 0 \\
\hline & RS 28 & Mixed-method & Results & 0 & 1 & 4 & 0 & 5 \\
\hline & RS 29 & Quantitative & Results & 0 & 0 & 0 & 0 & 0 \\
\hline & RS 30 & Quantitative & Results & 0 & 0 & 0 & 0 & 0 \\
\hline \multicolumn{4}{|c|}{ No. of educational papers containing the step/s } & 3 & 1 & 6 & 5 & 8 \\
\hline \multicolumn{4}{|c|}{ No. of occurrences in educational mixed-method RSs } & 3 & 1 & 7 & 1 & 12 \\
\hline \multicolumn{4}{|c|}{ No. of occurrences in educational RSs } & 9 & 1 & 18 & 8 & 36 \\
\hline \multicolumn{9}{|c|}{ Results sections in both disciplines } \\
\hline \multicolumn{4}{|c|}{ Total no. of papers containing the step/s in both corpora } & 9 & 3 & 14 & 9 & 18 \\
\hline \multicolumn{4}{|c|}{ No. of occurrences in quantitative RSs in both corpora } & 6 & 0 & 26 & 10 & 42 \\
\hline \multicolumn{4}{|c|}{ No. of occurrences in qualitative RSs in both corpora } & 7 & 1 & 1 & 4 & 13 \\
\hline \multicolumn{4}{|c|}{ No. of occurrences in mixed-method RSs (both corpora) } & 14 & 2 & 24 & 3 & 43 \\
\hline
\end{tabular}

choices that need to be highlighted in preparing teaching materials suited to the needs of novice writers in their attempt to write the section concerned in a research report [24].

\section{RESULTS}

Using the methods described above, the researcher has found that 'describing research conditions' is a rhetorical move that may be accomplished in four different ways in the Results section. All the constituent steps taken are closely associated with the delineation of the research circumstances under which the results were obtained. It is in this move that important information is furnished to help readers understand the conditions in which different sets of results were obtained. When it is described in a matrix clause or separate sentence, it constitutes one of the steps of 'describing research conditions'; however, it may also be embedded in another rhetorical move called 'presenting findings' when it merely appears as a phrase or subordinate clause that forms part of a matrix clause that presents a research result. The preparatory steps (before the presentation of findings) used in describing research methods in the Results sections are vital in providing a rationale behind the writers' attempt to collect and analyse the results.

Table 4 indicates the distribution of the rhetorical steps in 'describing research conditions' in the corpora of research papers in the two disciplines. It shows that a total of $98 \mathrm{oc}-$ currences of procedural categories have been identified in the two corpora. Interestingly, $63.30 \%(62 / 98)$ of the occurrences of steps 1-4 have been found in the linguistic corpus of Results sections whereas merely $36.7 \%$ (36/98) of the procedural steps appear in the educational corpus. The lower incidence of steps 1-4 in the educational Results sections may partly be ascribed to the likelihood that educational research reporters prefer to describe research conditions only in the preceding Method section/s. According to the results of the Mann-Whitney U-test (see Table 5), the asymptotic value for the occurrences of the four steps across the two disciplines is 0.324 , thus showing that the inter-disciplinary difference is still not significant in the overall occurrences of the steps in the Results sections.

Of the 62 occurrences of steps 1-4 in linguistic Results sections, $50.0 \%$ (31/62) have been found in mixed-method research papers which merely constitute $20 \%$ of all the linguistic Results sections. Nonetheless, as the p-value for the quantitative-qualitative comparison of linguistic Results sections (as shown in Table 5) is 0.081 (p.>0.05), the quantitative-qualitative difference in the occurrence of these four steps is still not significant.

Similarly, of the 36 occurrences of steps 1-4 in the educational Results sections, 44.4\% (16/36) appear in quantitative Results sections. On the whole, about the same proportions, which are $42.9 \%$ (42/98) and $43.9 \%$ (43/98) of steps $1-4$ appear in the quantitative and mixed-method Results sections respectively in the two corpora whereas merely $13.3 \%$ (13/98) of such occurrences appear in the qualitative Results 
Table 5. Asymptotic Significance Values (Two-Tailed p-Values) Indicating Inter-Disciplinary and Inter-Procedural Differences with Reference to Occurrences of the Procedural Steps (Using the Mann-Whitney U-Tests)

\begin{tabular}{|c|c|c|c|c|c|c|c|c|}
\hline \multirow[t]{3}{*}{$\begin{array}{l}\text { Rhetorical } \\
\text { Category }\end{array}$} & \multicolumn{2}{|c|}{$\begin{array}{l}\text { Inter-Disciplinary Comparison } \\
\text { (Applied Linguistics/ Education) }\end{array}$} & \multicolumn{6}{|c|}{$\begin{array}{c}\text { Inter-Procedural Comparison } \\
\text { (Quantitative/Qualitative) }\end{array}$} \\
\hline & \multirow{2}{*}{$\begin{array}{c}\text { Mann-Whitney } \mathbf{U} \\
\text { statistic (U) }\end{array}$} & \multirow{2}{*}{$\begin{array}{l}\text { p-value } \\
\text { (2-tailed) }\end{array}$} & \multicolumn{2}{|c|}{ Applied Linguistics } & \multicolumn{2}{|c|}{ Education } & \multicolumn{2}{|c|}{ Applied Linguistics and Education } \\
\hline & & & $\mathbf{U}$ & p-value & $\mathbf{U}$ & p-value & $\mathbf{U}$ & p-value \\
\hline Step 1 & 93.000 & 0.317 & 15.500 & 0.598 & 18.000 & 1.000 & 67.000 & 0.683 \\
\hline Step 3 & 89.500 & 0.300 & 3.000 & 0.007 & 11.000 & 0.181 & 27.000 & 0.003 \\
\hline Step 4 & 110.000 & 0.898 & 9.000 & 0.058 & 17.500 & 0.924 & 54.000 & 0.195 \\
\hline Steps $1-4$ & 89.500 & 0.324 & 7.500 & 0.081 & 15.500 & 0.668 & 44.500 & 0.094 \\
\hline
\end{tabular}

sections (that constitute $40 \%$ of the all the Results sections in both corpora). Given that the p-value for the quantitativequalitative comparison of all steps in educational Results sections (see Table 5) is 0.668 ( $p>0.05$ ), the quantitativequalitative difference is also not significant. The data have provided evidence showing that even though the Results sections based on quantitative and mixed-method research procedures in each corpus are slightly more inclined (than those based on qualitative research methods) to incorporate procedural steps, the difference is not significant enough.

With regard to the Kruskal-Wallis H-Test results (as shown in Table 6), it needs to be pointed out that the asymptotic value of 0.006 for Step 3 in the linguistic corpus is much lower than the cut-off point of 0.05 , thus illustrating that that there is a significant inter-procedural difference in regard to the frequencies of 'recounting data analysis procedures', which is obviously frequent in qualitative and mixedmethod studies but completely absent in qualitative linguistic Results sections. A significant difference has also been recorded for steps 1-4 in linguistic RSs alone ( $\mathrm{p}=0.017)$, but not in educational RSs $(\mathrm{p}=0.505)$. All other $\mathrm{p}$-values obtained for the comparisons of occurrences across three research procedures (i.e., quantitative, qualitative, and mixedmethod research procedures) in the each corpus are more than 0.05 for each step, thus showing that there are no other significant inter-procedural differences in each discipline. However, when both disciplines are considered as a whole, the asymptotic values for step 3 and steps $1-4$ are 0.001 and 0.017 respectively (both being less than 0.05 ), thus showing that there are significant inter-procedural differences for step 3 and steps 1-4.

On the one hand, $66.7 \%$ (10/15) of the linguistic Results sections incorporate at least one form of procedural steps, and four of the five linguistic Results sections that are void of procedural steps are papers based on qualitative research procedures. On the other hand, $53.3 \%(8 / 15)$ of the educational Results sections contain procedural steps and they comprise those using quantitative, qualitative and mixedmethod research procedures. Detailed explanations on each of the four procedural steps, their frequencies of occurrence and respective linguistic mechanisms will be presented in the ensuing subsections.

\section{Step 1: Relating Data Collection Procedure/s}

Research conditions can be described by first relating the procedures employed in collecting the data from (i) a set of respondents and/or a database in both linguistic and educational research papers, or (ii) a corpus of papers in applied linguistics. Despite the fact that writers of research papers in applied linguistics are expected to present findings in the Results section, it is interesting to note that findings may often be preceded or interspersed by procedures for data collection, which in fact, enlighten the readership on the conditions in which the results were obtained. Even though this

Table 6. Asymptotic Significance Values (p-Values) Indicating Inter-Procedural Differences with Reference to Occurrences of the Commentary Steps (Using the Kruskal-Wallis H-Tests)

\begin{tabular}{|c|c|c|c|c|c|c|}
\hline \multirow{2}{*}{ Rhetorical Category } & \multicolumn{4}{|c|}{ Type of Research Procedure (Quantitative/Qualitative/Mixed Method) at df = 2 } \\
\cline { 2 - 7 } & \multicolumn{2}{|c|}{ Applied Linguistics } & \multicolumn{2}{|c|}{ Education } & \multicolumn{2}{c|}{ Applied Linguistics and Education } \\
\cline { 2 - 7 } & Kruskal-Wallis Chi Square (H) & p-value & H & p-value & H & p-value \\
\hline \hline Step 1 & 4.726 & 0.094 & 0.389 & 0.823 & 4.340 & 0.114 \\
\hline Step 2 & 1.885 & 0.390 & 4.000 & 0.135 & 4.833 & 13.012 \\
\hline Step 3 & 10.103 & 0.006 & 3.237 & 0.198 & 0.089 & 0.001 \\
\hline Step 4 & 3.708 & 0.157 & 0.036 & 0.982 & 1.778 & 0.411 \\
\hline Steps 1 - & 8.099 & 0.017 & 1.367 & 0.505 & 8.166 & 0.017 \\
\hline
\end{tabular}


preparatory step may generally be found in the Method section of a research article, it can also appear in the Results section as a way of drawing the reader's attention to how data were collected. Such a step may (i) provide information on the relevance of the results to be presented, and (ii) enable readers to distinguish the different subsets of results which are presented together in the Results section. 'Relating the data collection procedure/s' is particularly relevant if the preceding Method section has not provided a sufficiently detailed description of the ways in which the data were collected.

Being a procedural category in the Results section, step 1 is more prevalent in the Results sections of linguistic research articles, as $40 \%(6 / 15)$ of the linguistic RSs include it while only $20 \%$ (3/15) of the educational RSs incorporate this step. In terms of frequencies, $66.7 \%$ (18/27) of the occurrences of this step are found in the linguistic Results sections whereas merely $33.3 \%$ (9/27) of them appear in the educational corpus. Nonetheless, the p-value for the interdisciplinary comparison of occurrences for Step 1 (using the Mann-Whitney U-test) is 0.317 (see Table 5), thus showing that the inter-disciplinary difference in terms of the frequencies is not significant. Likewise, the quantitative-qualitative comparison (see Table 5) and inter-procedural comparison (see Table 6) have yielded p-values which are all more than 0.05 , thus showing that there are no significant quantitativequalitative and inter-procedural differences in the occurrences of step 2 . On the whole, merely $30 \%$ (i.e., 9/30) of the papers in the two corpora incorporate descriptions of data collection procedures in their Results sections. The communicative functions of this step and their linguistic mechanisms are discussed as follows.

\section{(i) Describing the Research Instrument}

The communicative function involved in 'relating data collection procedure/s' can be accomplished through a description of the research instrument employed. The instrument may be described with reference to (i) the research tools used, such as questionnaires and think-aloud protocols, and (ii) methods of measurement involved in designing the instrument in both disciplines. The following instances show how an instrument is described before findings are presented.

1. Questions 2-6 of the pre-post questionnaire were on self-efficacy. Self-efficacy affects students' belief in their ability to succeed in a task. Factors that would affect self-efficacy would be their feeling about writing (question 2), the challenges they faced when writing (question 3)... (RS 7: 282).

2. Questions 11 and $\mathbf{1 2}$ asked students to assess their learning progress. (RS 16: 147).

While the aforementioned examples illustrate that noun phrases referring to the items or parts used in the instrument (e.g., 'questionnaire', 'question 2', 'questions', etc.) constitute a salient feature of step 1, research procedures may be described through a more detailed delineation of the ways in which variables are measured using the items included in the instrument as shown below:

3. To determine the degree to which learners were successful at inferencing, I and an experienced native-
English-speaking teacher independently rated their responses to each of the unknown words using a 3point scale $(2=$ successful, $1=$ partially successful, 0 = unsuccessful). (RS 3: 653).

4. I defined strategies as conscious cognitive or metacognitive activities that the learner used to gain control over or understand the problem without any explicit appeal to any knowledge source as assistance...(RS 3: 655).

5. Strategies can, in fact, often be broken down to a number of informational operations designed to accomplish a specific task such as learning or completing an assignment ... (RS 6: 55).

The examples above show that writers describe the instruments concerned by referring to parts of the data collection procedures that deal with how variables have been measured. This explains why definitions of variables become a prerequisite for the measurement. This sub-step that focuses on the measurement of a variable is characterised by means adjunct indicating divisions (e.g., 'using a 3-point Liker scale') or verbs indicating differentiation or categorisation (e.g., 'defined', 'can be broken into', etc.) given that writers need to inform the readership of the ways in which the instrument was used to measure each variable while collecting the data.

\section{(ii) Indicating Steps in Data Collection}

This is a more prominent sub-step in which the focus is not exclusively on the description of the instrument, but on the steps taken chronologically as shown below:

6. We turned next to the NOM sessions that occurred between the two storytellings to determine whether and how these sessions might have contributed to the quality of the retellings. (RS 2: 312)

7. To determine the different types of strategies and knowledge sources learners used, I had all the introspective think-aloud protocols initially transcribed verbatim before being carefully examined and coded twice, once by me and then by a colleague. (RS 3: 655)

8. The norms were identified on the basis of 20 wholeclass discussions recorded in Paula's classroom $(5 \mathrm{~h}$, $22 \mathrm{~min}$ ) and 23 whole-class discussions recorded in Luke's classroom (5 h, $52 \mathrm{~min}$ ). (RS 23: 258)

The instances illustrate that investigative verbs (e.g., determine', 'identified') or procedural verbs in the past tense (e.g., 'turned', 'had...transcribed', 'examined', 'were identified', 'recorded', etc.) are frequently used in describing conditions pertaining to the data collection procedures. Even though these steps do not form part of the findings, they provide a lead that shows readers a set of results collected under the circumstances involved. As these steps are described, lexemes indicating stages of development or transition (e.g., 'began', 'turned', 'next', etc.) also become a salient feature of this rhetorical step in linguistic research papers. More distinctly, this sub-step involves the use of interactive verbs as shown below: 
9. At the end of the research period, pupils were again asked to report how often they used English in outof-school activities. (R2 5: 765)*.

10. Although the students were requested to "work together' to solve the problem, each member had an individual worksheet on which he or she was asked to record the procedures carried out jointly or individually. (RS 23: 260)*.

Given that this sub-step involves interactions between researchers and respondents, instructional verb phrases (e.g., 'were asked', 'were requested', 'was asked', etc.) are often used to distinguish it from other rhetorical categories. A more prominent characteristic of this sub-step has to do with the use of temporal adverbials indicating the timing of the data collection procedures. As shown in Table 7, the temporal adverbials are either temporal adjuncts or temporal adverbial clauses beginning with temporal conjunctions or prepositions (e.g., 'during', 'before', after', etc.) whereas the main clauses usually consist of procedural verbs in the past simple tense referring to actions taken in collecting the data.

\section{Step 2: Justifying Data Collection Procedure/s}

Related to the statement of data collection procedure/s above is the justification of a set of procedures which may appear in the form of a separate sentence constituting the step. 'Justifying data collection procedure/s' is rarely found in the Results sections of both disciplines, as $13.3 \%(2 / 15)$ of the linguistic Results sections include it while only $6.7 \%$ (1/15) of the educational Results sections incorporate this step. It is therefore understandable that the p-value for the inter-disciplinary comparison of occurrences for Step 2 (using the Mann-Whitney U-test) is 0.550 (as shown in Table 5), thus indicating that there is no significant difference in terms of cross-disciplinary comparison of step 2. Likewise, the quantitative-qualitative comparison (see Table 5) and inter-procedural comparison (see Table 6) have yielded pvalues which are all more than 0.05 , thus showing that there are no significant quantitative-qualitative and interprocedural differences in the occurrences of step 2 .

These procedures may be justified with the intention of raising the readers' confidence in the validity and acceptability of the results to be presented. Examples of such justifications are given as follows:

11. Because it was possible to arrive at a completely accurate semantic meaning of a word and yet associate the word with a wrong syntactic category (Gass, 1999), for rating purposes, we classified responses that were semantically appropriate but syntactically deviant, or vice versa, as partially successful. In order not to underestimate learners' success, if the meaning or the definition they provided made sense in the context but when judged out of context was not the meaning of the word, we still considered the response partially successful... (RS 3: 652).

12. The advantage in such a breakdown is that it shows how outlines in which the student marks implicit connections - that is, uses manipulation - are qualitatively different from those in which the student simply extracts the connections that were already indicated in a source... (RS 6: 55).

13. Due to the alignment of learning activities, assessment and learning outcomes it was considered important in outcomes-based assessment to have some indication of whether students were aware of the module learning outcomes... (RS 28: 271).

The examples given above show that before findings are presented, the data collection procedures may be justified first by using reason or purpose adjuncts (e.g., 'Because it was possible to arrive at a completely accurate semantic meaning of a word and yet associate the word with a wrong syntactic category', 'In order not to underestimate learners' success', 'Due to the alignment of learning activities, assessment and learning outcomes', etc.) to show that the writers have been prudent enough to take note of some possible occurrences in data collection which might have inadvertently affected the acceptability of the results. Writers may (i) highlight the linkage between a variable to be measured and other related variables, or (ii) resort to past researchers' supportive statements in order to convince readers into accepting their procedure for collecting the data (e.g., categorising the responses). It is therefore understandable that lexemes and phrasal combinations carrying positive connotations (e.g., 'completely accurate', 'advantage', 'important', etc.).

The instances given below illustrate more distinctly the justification of a data collection procedure:

14. During initial rating, we obtained an interrrater agreement of $94 \%$. We then resolved disagreements through subsequent discussion to reach $100 \%$ interrater agreement on all items. (RS 3: 652).

15. However, the initial set of responses was reexamined in view of some participants' indications during the reading and retrospective interviews...(RS 3: 652).

Table 7. The Use of Sentence-Initial Subordinate Temporal Adverbials in Step 1 (i.e., 'Relating Data Collection Procedure/s')

\begin{tabular}{|l|l|}
\hline $\begin{array}{l}\text { Preceding Temporal Adverbials } \\
\text { (temporal adjunct/clause) }\end{array}$ & $\begin{array}{l}\text { Ensuing Matrix Clause } \\
\text { (containing procedural verb in the past simple tense) }\end{array}$ \\
\hline \hline During their second year of study, & pupils were placed in eight different classes, with three different teachers. (RS 5: 766) \\
\hline$\underline{\text { At the beginning of each interview, }}$ & I offered the focal learners the choice of speaking in Indonesian or English. (RS 5: 768) \\
\hline$\underline{\text { Before the students } \underline{\text { started }} \text { the course }}$ & they all responded to the self-report questionnaire concerning their goals. (RS 25: 127) \\
\hline$\underline{\text { After every group task }}$ & the students answered the task-specific questionnaire. (RS 25: 127) \\
\hline$\underline{\text { After the students finished the task, }}$ & $\begin{array}{l}\text { they filled out the task-specific questionnaire which reflected their personal interpretations of the group work. } \\
\text { (RS } 25: 128)\end{array}$ \\
\hline
\end{tabular}


The examples do not constitute part of the findings as they merely indicate the extent to which the rating done on the learners' responses was in accordance with an acceptable procedure. It is therefore a way of justifying the procedure for rating the learners' responses. The step is therefore characterised not merely by procedural verbs in the past tense, but also phrases denoting acceptability and prudent consideration (e.g., 'resolved disagreement', 're-examined', etc.).

\section{Step 3: Recounting Data Analysis Procedure/s}

Data analysis procedures are usually mentioned when linguistic research papers involve a group of subjects particularly in (i) quantitative studies involving more than 30 subjects, or (ii) qualitative studies involving not more than 20 subjects. 'Recounting data analysis procedure/s', as a procedural step, are the most prevalent in both corpora. In the Results sections of linguistic research articles, as $53.3 \%$ $(8 / 15)$ of the linguistic Results sections include it whereas $40 \%(6 / 15)$ of the educational Results sections incorporate this step.

In terms of frequencies, $64.7 \%(33 / 51)$ of the occurrences of this step are found in the linguistic Results sections whereas merely $35.3 \%$ (18/51) of them appear in the educational corpus. The p-value for the inter-disciplinary comparison of occurrences for Step 3 (using the Mann-Whitney Utest) is 0.300 , thus indicating that there is no significant difference between linguistic and educational researchers in terms of the likelihood to recount data analysis procedures in their Results sections. On the whole, even though $46.7 \%$ (i.e., 14/30) of the Results sections in the two corpora incorporate 'recounting data analysis procedure/s', a vast majority (50/51) of the occurrences of this step appear in the quantitative and mixed-method RSs, and merely one occurs in the qualitative RSs. More specifically, 48.5\% (i.e., 16/33) and $51.5 \%$ (i.e., 17/33) of the occurrences in the linguistic corpus are quantitative and mixed-method RSs, none of qualitative linguistic RSs contain 'recounting data analysis procedure/s' (see Table 4). Using the Mann-Whitney U-test, the p-values of 0.007 and 0.181 obtained for the linguistic RSs and educational RSs respectively (see Table 6) have shown that there is a significant quantitative-qualitative difference in the linguistic RSs but not in the educational RSs. Overall, when the two disciplines are considered as a whole, the p-value of 0.003 shows that a significant quantitative-qualitative difference exists in the occurrences of step 3 in both disciplines.

When all the three types of research procedures are considered, the p-value obtained for linguistic RSs and educational RSs are 0.006 and 0.198 respectively (see Table 6), thus showing that a significant inter-procedural difference exists in the linguistic corpus but not in the educational corpus. When both linguistic and educational RSs are considered as a whole, the asymptotic value is 0.001 (see Table 6), thus showing that inter-procedural difference for both corpora is significant.

This step is characterized by noun phrases which refer directly to the names of analysis procedures (e.g., 'coding', 'ANOVA', 'regression analysis', 'correlation analysis', etc.) which show how the data were analysed to provide more detailed information, such as the significance of differences in the contribution of certain variables as exemplified below:
16. Coding involved reading and rereading the protocols and identifying in an inductive manner the kind of inferencing strategies and knowledge sources used. (RS 3: 655).

17. An ANOVA conducted on the means of success for strategies and a two-way chi-square test conducted on the strategy types and their proportion of success revealed a statistically significant difference in the contribution of different strategies - ANOVA: $\mathrm{F}(6$, $464)=8.85, \mathrm{p}<.001 ; \chi^{2}=51.10, d f=12, \mathrm{p}, .001 .(\mathrm{RS}$ 3: 660).

18. The Regression Analysis is a statistical technique for evaluating the joint and separate influences the independent variable(s) (IV) has on the dependent variables (DV). The value given, the "Coefficient of Determination" or "R square" (R2), indicates the importance the corresponding IVs have in determining the predicted value of the DV. An "Enter Method of Regression", analysis is carried out in which all the explanatory variables are entered to be analysed. (RS 10: 170).

As shown above, salient features of step 3 are related to the use of (i) procedural verbs pertaining to execution/implementation (e.g., 'conducted', 'is carried out', 'was performed', etc.), and (ii) investigative procedural verbs (e.g., 'identifying', 'evaluating', 'determining', etc.). Other more distinct investigative procedural verbs are exemplified below:

19. The correlation analysis investigates the nature and strength of the relationship among the variables. The main difference between the two analyses is that correlation analysis analyses the variables in pairs whereas regression analysis does it in groups. (RS10: 173)*.

20. Prior to comparing children with regard to parents and teachers' evaluations, correlation analyses examined the relations between parents' evaluation of children's temperamental characteristics and of children's socioemotional adjustment... (RS 21: 223)*.

21. In order to examine the impact of perceived parental support on socioemotional adjustment of children, they were classified in one of the two following groups:.. (RS 18: 161)*.

The aforementioned instances illustrate that investigative procedural verbs (e.g., 'investigates', 'examined', 'analyses', 'examined', 'were classified', etc.) are often used in collocation with nouns denoting variable association (e.g., 'relationship', 'relations', 'impact', etc.). These lexemes are used to signal the accomplishment of analysis procedures that study connections between different variables.

The aforementioned procedural verbs, however, are prominent in the subject-predicator-adverbial structures as shown in Tables $\mathbf{8}$ and $\mathbf{9}$. In a sentence containing the subject-predicator-adverbial/s (SPA) structure that delineates a data analysis procedure, the passive procedural verb is usually (i) preceded by a noun phrase denoting a data analysis procedure, instrument or a set of processed data, and (ii) ensued by a purpose adjunct in the form of a infinitive clause (as shown in Table 8) or a means adjunct indicating how the 
Table 8. Using Infinitive Clauses in SPA Structures for 'Recounting Data Analysis Procedure/s' in Step 3

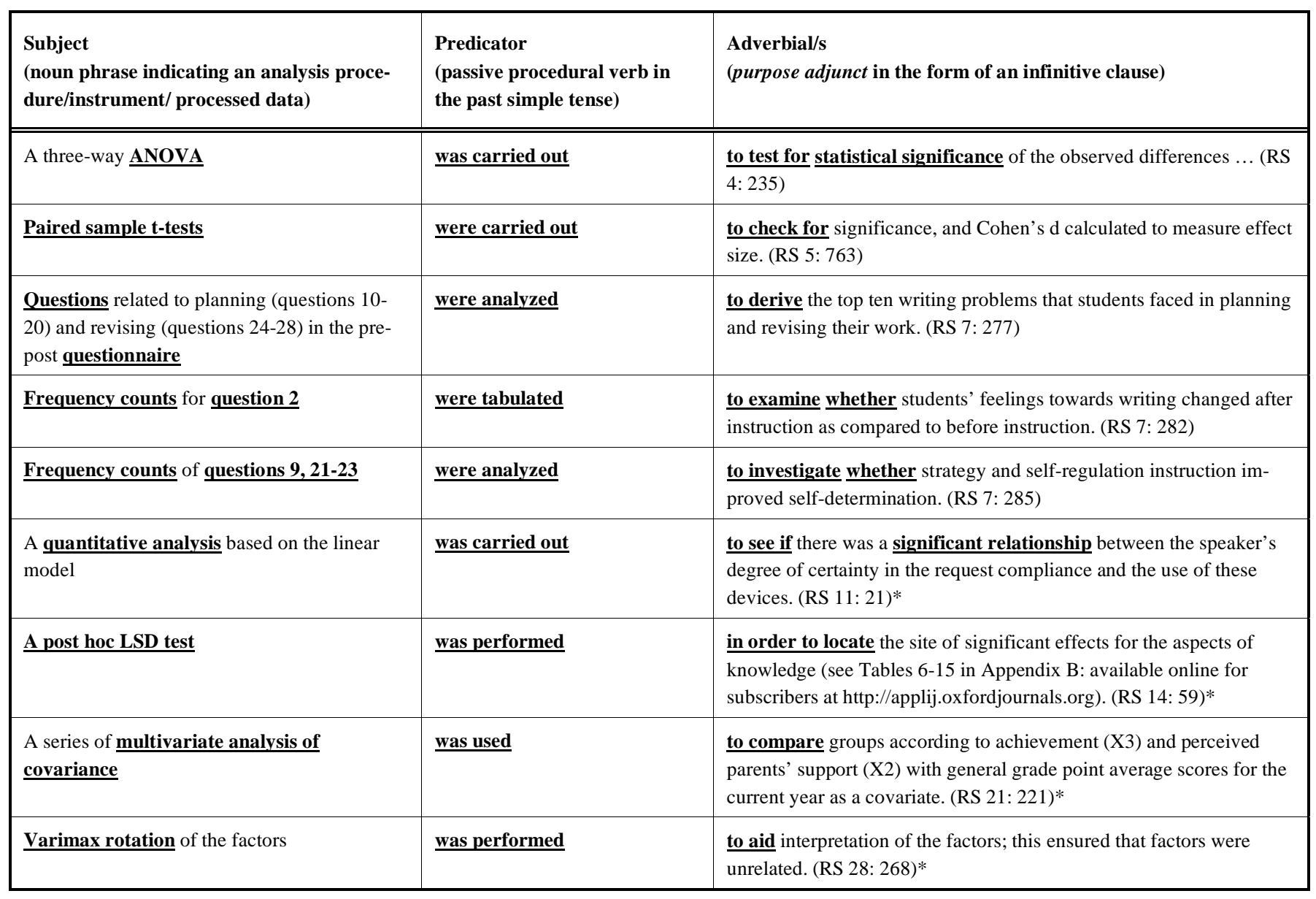

Table 9. Using Means Adjuncts in SPA Structures for 'Recounting Data Analysis Procedure/s' in Step 3

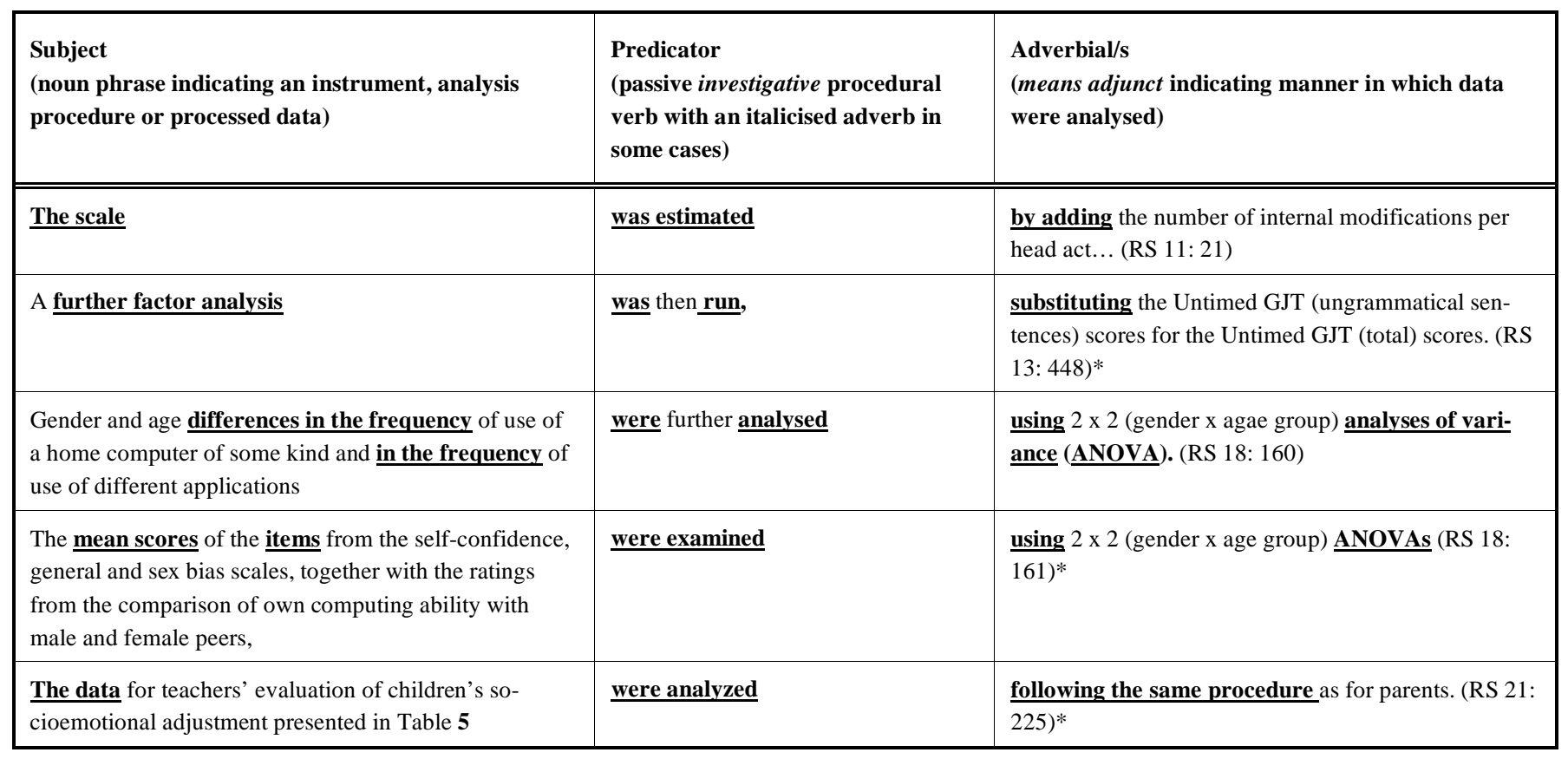


Table 10. Using Means Adjuncts in ASPA Structures for 'Recounting Data Analysis Procedure/s' in Step 3

\begin{tabular}{|c|c|c|c|}
\hline $\begin{array}{l}\text { Adverbial } \\
\text { (purpose adjunct or } \\
\text { prepositional phrase) }\end{array}$ & $\begin{array}{l}\text { Subject } \\
\text { (noun phrase indicating an in- } \\
\text { strument, analysis procedure, } \\
\text { variable or data) }\end{array}$ & $\begin{array}{l}\text { Predicator } \\
\text { (procedural verb indicat- } \\
\text { ing investigation or exe- } \\
\text { cution ) }\end{array}$ & $\begin{array}{l}\text { Adverbial/s } \\
\text { (means adjunct) }\end{array}$ \\
\hline $\begin{array}{l}\text { To determine whether } \\
\text { there were any overall } \\
\text { differences among the } \\
\text { treatment groups, }\end{array}$ & $\frac{\text { a multivariate analysis of }}{\underline{\text { variance }} \text { (MANOVA) }}$ & was performed & $\begin{array}{l}\text { using the scores on the } 10 \text { dependent measures (produc- } \\
\text { tive orthography, receptive orthography, receptive recall } \\
\text { of meaning and form, receptive recognition of meaning } \\
\text { and form, productive association, receptive association, } \\
\text { productive syntax, receptive syntax, productive grammar, } \\
\text { and receptive grammar). (RS 14:58)* }\end{array}$ \\
\hline $\begin{array}{l}\text { To determine whether } \\
\text { the phonological cue } \\
\text { used in the productive } \\
\text { knowledge of orthogra- } \\
\text { phy test had an effect } \\
\text { on the scores of the } \\
\text { experimental groups, }\end{array}$ & $\begin{array}{l}\text { a one-way analysis of variance } \\
\underline{\text { ANOVA) }}\end{array}$ & was performed & $\begin{array}{l}\text { using the scores for the single encounter group and the } \\
\text { control group from the test of productive knowledge of } \\
\text { orthography. (RS } 14: 60)^{*}\end{array}$ \\
\hline In this study & $\begin{array}{l}\text { the students' motivational goals and } \\
\text { regulation of motivation }\end{array}$ & $\underline{\text { was studied }}$ & $\begin{array}{l}\text { both from an individual student's perspective as well } \\
\text { as that of a group of students in socially shared group- } \\
\text { learning tasks.(RS 25: } 127)^{*}\end{array}$ \\
\hline
\end{tabular}

data were analysed (see Table 9). Closely related to the SPA structure is another prevalent pattern for recounting data analysis procedures as illustrated in Table $\mathbf{1 0}$ (with the ASPA) in which the means adjunct also appears in the sentence-final adverbial, the only main difference being that the sentence-initial adverbial usually consists of a purpose adjunct or prepositional phrase.

A more recognizable feature that distinctly differentiates step 3 from other communicative categories in the Results sections has to do with the use of time-relationship adjuncts (e.g., 'first', 'third', 'then', etc.) as shown below:

22. To determine the relationship between successful inferencing and the strategies and knowledge sources used, I first calculated the percentage of successful, partially successful, and unsuccessful inferences for each strategy type and knowledge source. I then calculated a mean of success for each strategy type and knowledge source... (RS 3: 657-658).

23. The interviews were recorded, transcribed in note form, and then analysed through multiple listenings, coding, and the construction of a matrix to facilitate direct comparison of learners' comments to each other and to themselves at the three different points in time. (RS 5: 767)*.

24. Finally, we examined whether there were changes in each of the 15 questionnaire item responses. (RS 28: 270)*.

These time-relationship adjuncts are generally used to clearly distinguish the stages involved in analysing the data.

Another language mechanism that clearly indicates the stages has to do with the use of ordinal adjectives (e.g., 'the first', 'the second', etc.) as exemplified below:
25. The first series encompassed children's self-rated variables; the second encompassed children's temperamental characteristics as reported by parents whereas four series examined children's socioemotional variables as evaluated by parents and by teachers. (RS 21: 221)*.

26. The examination of parents' evaluation of children's socioemotional adjustment involved two multivariate analysis: the first combined withdrawal, insecurity and perfectionism (which refer to internal dimensions) and the second combined conduct problems, self-regulation and openness (which refer to more overt behaviors). (RS 21: 224)*.

27. In the first analysis, the criterion for determining the priority for entering variables in the stepdown analysis was based on ease of observable manifestations... (RS 21: 224)*.

A shown above, these noun phrases containing the ordinal adjectives are usually followed by implicative verbs (e.g., 'encompassed', 'involved', etc.) signaling inclusion or entailment. In all the aforementioned examples involving the use of ordinal adjectives and time-relationship adjuncts, lexemes denoting investigation (e.g., 'calculated', 'analysed', 'breakdowns', 'comparison', 'examination' etc.) often collocate with procedural verbs indicating documentation (e.g., 'recorded', 'transcribed', etc.) in recounting data analysis procedures.

Overall, while a larger portion of the aforementioned procedural verbs are in the past simple (such as 'conducted', 'analysed', 'examined', etc.), a considerable number of them are presented in the present simple (e.g., 'is carried out' and 'analyses' in RS 10). Such an interesting phenomenon in tense usage would become more evident as we examine the following instances: 
28. Newman-Keuls $(\mathrm{p}<0: 05)$ was used as a post hoc analysis to further examine achievement group effect. Newman-Keuls (po0:05) was used as a post hoc analysis to further examine achievement group effect. Cohen's d-statistic was used to calculate effect size. Similarly to Siderisis (2005), we used Cohen's conventions of a small effect size (E.S. 1/4 .3) ...(RS 21: 221)*.

29. The data of two groups of four students is presented so that the qualitative analysis of the task-specific questionnaire responses and the analysis of the video data is combined from each of the three collaborative learning tasks. For every three tasks both student group profiles are first constructed from the students' questionnaire answers. The video data analy$\underline{\text { sis is used to give another, process-oriented perspec- }}$ tive on group working and collaboration. (RS 25: 128)*.

The instances above indicate that both the present and past tenses can be used in recounting data analysis procedures; nonetheless three important features warrant attention here. First, past tenses are far more prevalent than the present tenses. Second, past tenses are used in linguistic corpus while both the past and present tenses may appear in the educational corpus. Third, despite the presence of both tenses in the linguistic and educational corpora, consistency is always demonstrated in tense usage. This means that when the authors begin using the present tense for recounting the data analysis procedure, the same tense is always used in presenting descriptions with the same communicative function.

\section{Step 4: Justifying Data Analysis Procedure/s}

'Justifying data analysis procedure/s' generally occurs only if the Results section also includes 'recounting data analysis procedure/s' (RDAP), but it may appear in the Results sections in cases where RDAP has already been presented in the preceding Method section. It is used to (i) highlight the acceptability of the analysis procedures, and (ii) emphasise that a particular step (such as the step to consider the effect of a certain factor affecting the accuracy of the findings) has been taken to ensure reliability of the result/s. Even though this step can be found in both linguistic and educational research papers, it occurs more frequently in educational research reports.

'Justifying data analysis procedures', as a procedural step, is found in the Results sections of both linguistic end educational research articles, as $26.7 \%$ (4/15) of the linguistic Results sections and $33.3 \%(5 / 15)$ of the educational Results sections incorporate the step. In terms of frequencies, $52.9 \%(9 / 17)$ of the occurrences of this step are found in the linguistic Results sections, and likewise, $47.1 \%(8 / 17)$ of them appear in the educational corpus. On the whole, $30 \%$ (i.e., 9/30) of the Results sections in the two corpora incorporate 'justifying data analysis procedures', and most (58.8\% or $10 / 17)$ of the occurrences of this step appear in the quantitative Results sections. More specifically, $100 \%$ (i.e., 9/9) of the occurrences in the linguistic corpus have been found in the quantitative and mixed-method Results sections whereas $87.5 \%$ (i.e., 7/8) of the occurrences of this step in the educational corpus have been found in the qualitative and quantitative Results sections. The p-values for the interdisciplinary comparison and quantitative-qualitative comparison of the occurrences for Step 4 (using the MannWhitney U-test) in both disciplines are all more than 0.05 (see Table 5), thus indicating that there is no significant cross-disciplinary and quantitative-qualitative difference in the occurrences of step 4 . This means that educational researchers are almost as likely as applied linguists to incorporate justifications for their data analysis procedures in their Results sections on the whole. Likewise, inter-procedural comparison of the occurrences of step 4 (using the KruskalWallis H-test) has yielded p-values which are all more than than 0.05 (see Table 6), thus indicating no significant interprocedural difference in both disciplines as well.

There are some cases in which the justification in step 4 is embedded in the recounting of data analysis procedures in step 3. Instances of such examples are given below:

30. In order to get a more refined picture of which explanatory variables make the most contribution to the number of Errors, a different type of Regression study, "Stepwise Multiple Regression'" was carried out. (RS 10: 171)*.

31. To establish whether the within-group variance justified conducting correlational analyses, measures of skewness and kurtosis for all test scores (Implicit, Explicit, and IELTS total, listening, reading, speaking, and writing) were calculated for the IELTS subsample. (RS 13: 450).

32. A factor loading cut off of .45 was used for inclusion of a variable for interpretation of a factor (Comrey $\mathbf{\&}$ Lee, 1992). Using these criteria each item at each time point loaded on to a single factor. (RS 28: 268)*.

The two examples illustrated above indicate that the matrix clause contains the description of data analysis procedure (in step 3) while the justification (in step 4) is provided only in the subordinate clause which is a purpose adjunct in the sentence-initial position. Alternatively, as shown in the example extracted from RS 28 above, a past research methodologist's publication details (i.e. name/s and year of publication) may be cited only in parenthesis in an embedded justification which demonstrates that the analysis is not new or untested, and that its acceptability has been proven in previous research.

In contrast to the embedded justifications above, the following instances show that justifications are provided in the matrix clauses to demonstrate the extent to which the data analysed are acceptable:

33. I established the reliability of the coding by calculating an intercoder agreement on a sample of $20 \%$ of the data, selected from every fifth participant. The intercoder agreement for that $20 \%$ of the data was $89 \%$. The second coder and I resolved discrepancies through discussion to achieve $100 \%$ agreement. (RS 3: 655).

34. The reliabilities (alpha) for the three computer attitude subscales used in the present study were calculated and found to be: self-confidence, 0.65; general, 0.84; sex bias, 0.82. (RS 18: 161). 
35. Consistency of judgment between the two external researchers was obtained by inter-rater reliability, with the index of percentage agreement of presence. (RS 27: 351)*.

The instances given above indicate that justifications of the data analysis procedures generally focus on the extent to which the degree of agreement or consistency in judgment has been analysed and shown to be convincing. While there is no denying that the reliability is a measure of the extent to which repeated measures of a variable may produce the same result, it needs to be considered as a justification for data analysis procedure rather than data collection procedure. This means that writers' inclusion of reliability coefficients is generally associated with their intention to demonstrate that a proper analysis has been carried out to demonstrate the extent to which the data are trustworthy. In general, if the reliability coefficient is found to be low, the writers would have to collect data all over again till a sufficiently high reliability coefficient is obtained. In other words, reliabilities can be reported only after the data collected have been analysed and shown to be trustworthy and acceptable. As such, even though reliability coefficients are associated with how data were collected or obtained, their inclusion is actually concerned with the author's communicative intention to justify the entire procedure used for analysing the data.

Justification for an analysis procedure is also relatively overt in the following instances:

36. In this section I was able to build individual portraits of some depth and colour, to complement the broad picture deriving from the survey data. (RS 5: 767)*.

37. This analysis allows us to find the degree to which various combinations of independent variables (i.e. a model) explain the dependent variable. (RS 10: 171)*.

38. This solution, then, lends support to the claims that these tests provide relatively separate measures of implicit and explicit knowledge. (RS 13: 448)*.

The examples given above indicate that phrasal combinations signaling capability or compliance (e.g., 'was able to build individual portraits of some depth and colour', 'allows us to find the degree...', 'lends support to the claims...') are often used (prior to noun phrases) to highlight the caution exercised while considering the comprehensibility of the analysis procedure, or the prudence demonstrated in studying the relationships between different variables.

Equally salient is the use of past researchers' views to support one's data analysis procedures as exemplified below:
39. It is increasingly important that effect size, or practical significance, is (be) reported alongside significance $(\mathrm{p})$ values, as relying on p-values alone can result in researchers making unsound claims (Kirk 1996; Wilkinson 1999). (RS 10: 171)*.

40. As McCall et al. (2000) pointed out, in order to disentangle the correlates of having poor grades from being underachiever, it is necessary to control for grades. (RS 21: 221)*.

The authors may use past researchers' statements to demonstrate the degree to which they have taken note of important aspects that might have been overlooked in other studies, thus justifying the relative superiority of the analysis procedure. A prominent feature of this sub-step is the use of it-clauses indicating centrality (e.g., 'it is increasingly important...', 'it is necessary...', etc.) which is intended to draw readers' attention to a statistical procedure which has been incorporated on the basis past researchers' experience.

In comparison to the instances analysed, a much more overt and prominent structure in step 4 has to do with the use of reason adjuncts (e.g., 'Due to the number of participants in the study', Owing to the nature of the internal modifications contained in the corpus 'In view of the small sample size', etc.) as shown in Table 11. In order to demonstrate the accountability of their analysis procedure, authors may opt to candidly acknowledge the limitations of their research procedures so as to demonstrate their awareness of some shortcomings, thus augmenting the overall acceptability and trustworthiness of the analysis procedure/s. Table $\mathbf{1 1}$ shows that the sentence-initial reason adjunct which is in the form of a prepositional phrase (referring to a limitation) is more often ensued by a negative matrix clause (containing a negative procedural verb in each of the first three instances) to explain why a certain analysis procedure has not been undertaken.

\section{CONCLUSIONS AND IMPLICATIONS FOR THE TEACHING OF ESP}

The findings presented above have shown that writers in applied linguistics and education may describe the research conditions by (i) explaining data collection procedure/s, (ii) justifying the data collection procedures, (iii) recounting data analysis procedure/s, and/or (iv) justifying the data analysis procedure/s. Interestingly, $66.7 \%$ of the linguistic Results sections incorporate at least one form of procedural steps, but merely $53.3 \%$ of the educational Results sections contain procedural step/s. It has also been found that $63.3 \%$ of the occurrences of steps 1-4 have been found in the linguistic

Table 11. The Use of Sentence-Initial Reason Adjuncts in Step 4 (i.e., 'Justifying Data Analysis Procedure/s') in the Results Sections

\begin{tabular}{|l|l|}
\hline $\begin{array}{l}\text { Reason Adjunct } \\
\text { (prepositional phrase indicating a limitation) }\end{array}$ & $\begin{array}{l}\text { Matrix Clause } \\
\text { (containing procedural verb in the past simple tense) }\end{array}$ \\
\hline \hline$\underline{\text { Due to the number of participants in the study, }}$ & I did not analyze individual variations and their consequences. (RS 3: 656) \\
\hline $\begin{array}{l}\text { Owing to the nature of the internal modifications contained in } \\
\text { the corpus, (RS 11: 21)* }\end{array}$ & they could not be measured in terms of decreasing and/or increasing mitigating effects. \\
\hline $\begin{array}{l}\text { In view of the small sample size, and large number of } \\
\text { variables, }\end{array}$ & statistical analysis of the results is inappropriate. (RS 19: 255) \\
\hline
\end{tabular}


corpus of Results sections while only $36.7 \%$ of the procedural steps appear in the educational corpus.

At first glance, applied linguists seem to have a greater tendency to incorporate or reiterate procedural descriptions in the Results sections while educational research reporters seem to avoid describing research conditions in the RSs (even though they might do so in the preceding Method sections). However, a closer look via the Mann-Whitney U-Test has revealed that the inter-disciplinary difference is still not significant in the overall occurrences of the four steps in the Results sections $(p=0.324)$. This has led us to consider the quantitative-qualitative and inter-procedural differences. As the $\mathrm{p}$-value for the quantitative-qualitative comparisons of linguistic RSs and educational RS are 0.081 and 0.668 respectively, the quantitative-qualitative differences in the occurrences of these four steps are also not significant in both disciplines.

When three types of procedures are compared using the Kruskal-Wallis H-Tests, a significant difference has been recorded for step $3(\mathrm{p}=0.006)$ in only linguistic RSs, but no significant difference has been recorded for every step in educational RSs. As such, inter-procedural difference is likely to affect the occurrence of step 3 in the linguistic RSs. This also explains why 'recounting data analysis procedures' (step 3) is completely absent in qualitative linguistic RSs which are generally based on data obtained via observations and interviews.

About the same proportions (i.e., $42.9 \%$ and $43.9 \%$ ) of steps 1-4 appear in the quantitative and mixed-method Results sections respectively in the two corpora while only $13.3 \%$ of such occurrences occur in the qualitative RSs. Such a finding is further substantiated by the result of the Kruskal-Wallis test (conducted for all steps taken as a whole), which shows that a significant difference exists for steps $1-4$ considered as a whole $(\mathrm{p}=0.017)$ in only linguistic RSs, but no significant difference exists for all procedural steps in educational RSs. This means that inter-procedural difference is likely to affect the frequencies of procedural steps 1-4 taken as a whole only in the linguistic RSs. This also explains why most linguistic Results sections that are void of procedural steps are papers based on qualitative research procedures.

When occurrences of procedural steps in both corpora are added up and both disciplines are considered as a whole, significant inter-procedural differences have been found only for step $3(\mathrm{p}=0.001)$ and steps $1-4(\mathrm{p}=0.017)$. It can therefore be concluded that inter-procedural difference is likely to have a bearing on the frequencies of occurrence of step 3 (i.e., 'recounting data analysis procedures') and steps 1-4, but it is not likely to affect the occurrences of steps 1,2 and 4 in isolation. This also explains why qualitative RSs in both corpora (taken as a whole) have only one occurrence of step 3 (even though its occurrences are numerous in the other research papers employing other research procedures).

The findings obtained in this study have several important pedagogical implications. First, it is likely that qualitative analysts in applied linguistics normally avoid discussing or reiterating research methods (involving data collection and analysis procedures) in the Results sections (but may opt to do so exclusively in the preceding Method/s sections).
Novice writers of qualitative linguistic research papers may therefore be expected to only avoid such procedural descriptions while reporting their findings in their Results sections.

Second, even though we are aware that step 2 (unlike steps 1,2 and 4) is rare in both corpora, it is important to consider its pedagogical implications. Step 2 (i.e., 'justifying data collection procedures') is almost completely absent in the corpus of educational RSs and appears merely in one research report based on mixed-method research procedures. This may be due to the possibility that the educational researchers generally prefer to state and/or justify the procedures for gathering data only in the preceding Method section when necessity arises. In linguistic research papers, even though data collection procedures have been included in 40 percent of the Results sections, it is justified in only two papers (based on qualitative and mixed-method procedures respectively). In all the cases in which justifications of data analysis procedures occur, they are always related to the interpretation of subjects' qualitative data obtained through observations and interviews alone (and not quantitative data). This means that novice writers in both disciplines may, in general, be advised to exclude justifications of data collection procedures in quantitative Results section (even though they may opt to incorporate it in the preceding Method section).

Third, it is important to note that step 3 (i.e., 'recounting data analysis procedures') appears to be the most frequent procedural step (given that it occurs in most of the linguistic RSs and $40 \%$ of the educational RAs, and its occurrences are particularly frequent in the quantitative linguistic RSs). This means that even though 'recounting data analysis procedures' has often been regarded as part of the Method section in past research $[22,25]$, it actually occurs in most of the linguistic RSs and a considerably large portion of the educational RSs as well. Given the prevalence of step 3 in mixedmethod and quantitative RSs in applied linguistics, ESP teachers may recommend that the novice writers conducting such studies in linguistics consider the possibility of briefly recounting data analysis procedures before presenting their results. Such brief recounts may help readers to (i) distinguish different subsets of the results being reported, and (ii) understand the circumstances under which a particular result has been obtained.

Fourth, the use of step 4 in only certain RSs in both disciplines has shown that justifications of data analysis procedures are on the whole optional (and even completely absent in quantitative linguistic RSs). In fact, such justifications of data analysis procedures (step 4) are brief and may be incorporated by novice writers only when it is necessary to stifle potential criticisms against the validity of the research methods and their related findings.

Aside from the aforementioned findings related to interdisciplinary and inter-procedural comparisons, what also merits attention is an interesting repertoire of linguistic resources that can be used in the preparation of teaching material aimed at enlightening learners on how research methods are described and justified in presenting results. For example, ESP instructors may find it useful to highlight investigative procedural verbs while teaching learners to recount data analysis procedures in the presentation of results, especially as these verbs frequently collocate with nouns denoting fig- 
ures or values obtained from the whole sample of subjects or documents. Similarly, it is vital for learners to recognize procedural verbs in the past tense, means adjuncts and lexemes indicating transition or development in their attempt to distinguish the descriptions of research conditions from the presentation of results because such linguistic choices collectively constitute a salient feature of both 'relating data collection procedures' and 'recounting data analysis procedures' in the section which is mainly meant for presenting findings.

More specifically, even though certain linguistic features, particularly means adjuncts, may occur in both 'relating data analysis procedures' and 'recounting data collection procedures', learners may still be instructed to distinguish them by referring to the noun phrases they collocate with. For instance, means adjuncts in 'relating data collection procedures' generally collocate with noun phrases indicating items or parts of an instrument itself whereas those related to 'recounting data analysis procedures' co-occur with noun phrases denoting acceptability and reliability of research methods.

With regard to learners who are uncertain over how data collection and/or analysis procedures can be justified, it is recommended that they use a genre-based approach to learning by referring to segments of published texts, especially the Results section. In this section, reason/purpose adjuncts and phrases denoting methodological acceptability are used to demonstrate writers' professional expertise, particularly in taking note of certain possible occurrences that might have inadvertently affected the validity of the results. Another useful list of vocabulary items that learners should be exposed to in a course that comprises the description of research conditions has to do with lexemes with positive connotations in both linguistic and educational research papers.

In brief, the findings obtained in this study have shown that in the preparation of teaching materials aimed at developing novice writers' academic literacy, ESP instructors may first consider the possible differences in the frequencies of the rhetorical steps related to describing research conditions. The relative frequencies of the constituent steps, as discussed above, can indicate the extent to which emphasis needs to be placed on explaining them with reasons and examples. Subsequently, instructors may show learners how these rhetorical categories are similar to or different from one another in terms of the linguistic choices used to accomplish the communicative functions involved.

\section{ACKNOWLEDGMENTS}

I would like to thank the Malaysian University of Sabah for providing me with the Fundamental Research Grant that has made it possible to complete this pedagogically motivated investigation.

\section{APPENDIX 1: JOURNAL ARTICLES INCLUDED IN THE SAMPLE OF LINGUISTIC RESULTS SECTIONS}

\begin{tabular}{|c|c|}
\hline RS 1 & $\begin{array}{l}\text { Kamhi-Stein LD. Reading in two languages: How attitudes toward home language and beliefs about reading affect the behaviours of "unpre- } \\
\text { pared" L2 college readers. TESOL Quarterly 2003;37(1): 35-71. }\end{array}$ \\
\hline RS 2 & $\begin{array}{l}\text { Ko J, Schallert DL, Walters K. Rethinking scaffolding: Examining negotiation of meaning in an ESL storytelling task. TESOL Quarterly } 2003 \text {; } \\
37(2): 303-24 \text {. }\end{array}$ \\
\hline RS 3 & $\begin{array}{l}\text { Nassaji H. L2 vocabulary learning from context: Strategies, knowledge sources, and their relationship with success in L2 lexical inferencing. } \\
\text { TESOL Quarterly 2003; 37(4): 645-70. }\end{array}$ \\
\hline RS 4 & Liu J. Effects of comic strips on L2 learners' reading comprehension. TESOL Quarterly 2004; 38(2): 225-42. \\
\hline RS 5 & Lamb M. The impact of school on EFL learning motivation: An Indonesian case study. TESOL Quarterly 2007; 41(4): 757-80. \\
\hline RS 6 & $\begin{array}{l}\text { Newman M, Trenchs-Parera M, Pujol M. Core academic literacy principles versus culture-specific practices: A multi-case study of academic } \\
\text { achievement. English for Specific Purposes 2002;22(1): 45-71. }\end{array}$ \\
\hline RS 7 & $\begin{array}{l}\text { Ching LC. Strategy and self-regulation instruction as contributors to improving students' cognitive model in an ESL program. English for } \\
\text { Specific Purposes 2002; 21(3): 261-89. }\end{array}$ \\
\hline RS 8 & $\begin{array}{l}\text { Hewings M, Hewings A. "It is interesting to note that...": A comparative study of anticipatory 'it' in student and published writing. English for } \\
\text { Specific Purposes 2002; 21(4): 367-83. }\end{array}$ \\
\hline RS 9 & $\begin{array}{l}\text { Zhu W. Writing in business courses: An analysis of assignment types, their characteristics, and required skills. English for Specific Purposes } \\
\text { 2002; 23(2): 111-35. }\end{array}$ \\
\hline RS 10 & $\begin{array}{l}\text { Fuertes-Olivera PA, Go'mez-Martı́nez S. Empirical assessment of some learning factors affecting Spanish students of business English. Eng- } \\
\text { lish for Specific Purposes 2004; 23(2): 163-80. }\end{array}$ \\
\hline RS 11 & $\begin{array}{l}\text { Reiter RM, Rainey I, Fulcher G. A comparative study of certainty and conventional indirectness: Evidence from British English and Peninsular } \\
\text { Spanish. Applied Linguistics 2005; 26(1): 1-31. }\end{array}$ \\
\hline RS 12 & Cekaite A, Aronsson K. Language play, a collaborative resource in children's L2 learning. Applied Linguistics 2005; 26(2): 169-91. \\
\hline RS 13 & $\begin{array}{l}\text { Ellis R. Modelling learning difficulty and second language proficiency: The differential contributions of implicit and explicit knowledge. Ap- } \\
\text { plied Linguistics 2006; 27(3): 431-63. }\end{array}$ \\
\hline RS 14 & Webb S. The effect of repetition on vocabulary knowledge. Applied Linguistics 2007; 28(1): 46-65. \\
\hline RS 15 & iting for publication. Applied Linguistics 2007; 28(3): 440-65. \\
\hline
\end{tabular}




\section{APPENDIX 2: JOURNAL ARTICLES INCLUDED IN THE SAMPLE OF EDUCATIONAL RESULTS SECTIONS}

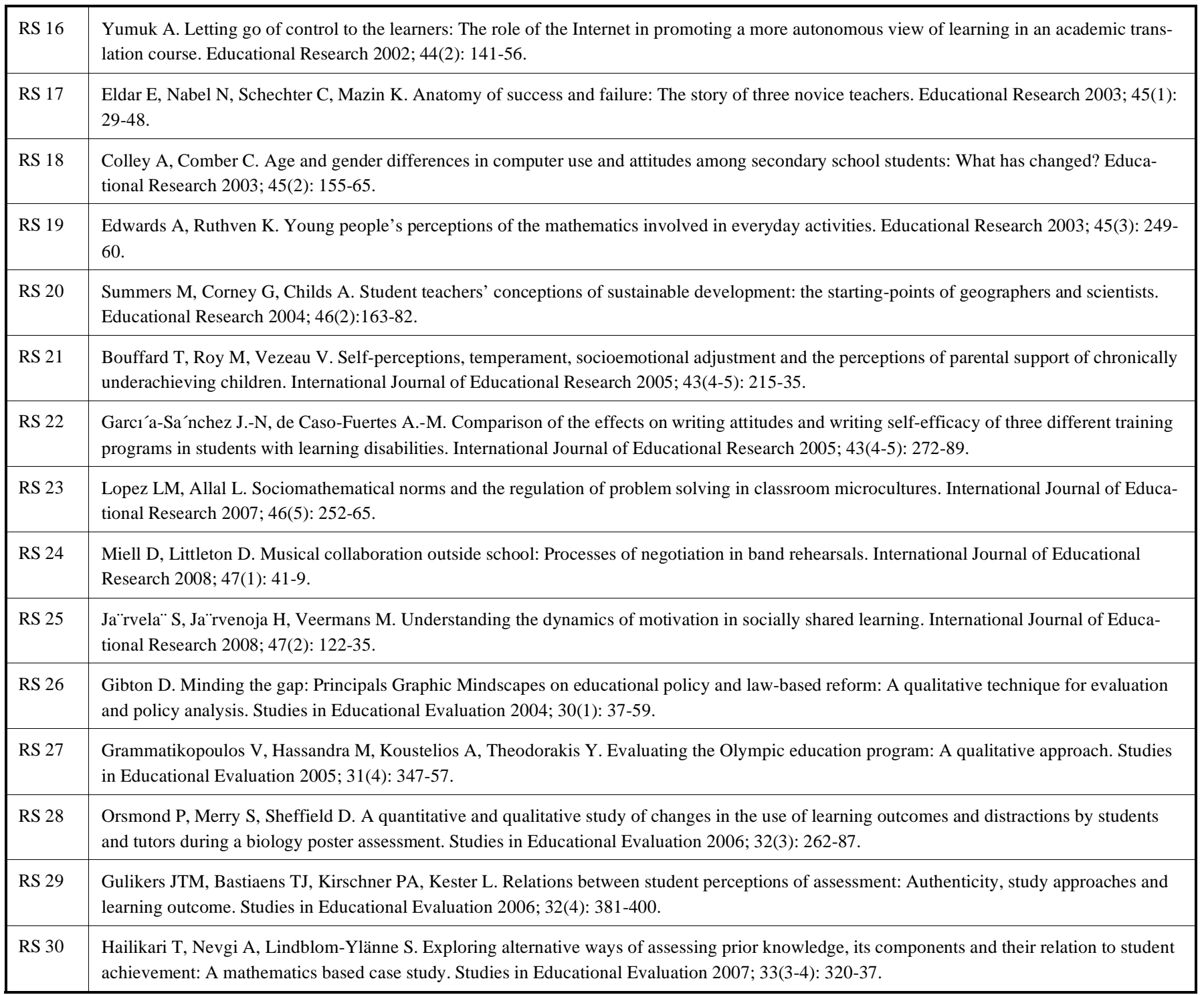

\section{REFERENCES}

[1] Swales JM. Genre analysis: English in academic and research settings. Cambridge: Cambridge University Press 1990.

[2] Gledhill C. The discourse function of collocation in research article introductions. Engl Specif Purposes 2000; 19(2): 115-35.

[3] Samraj B. An exploration of a genre set: Research article introductions in two disciplines. Engl Specif Purposes 2005; 24: 141-56.

[4] Brett P. A genre analysis of the results section of sociology articles. Engl Specif Purposes 1994; 13: 47-59.

[5] Williams IA. Results sections of medical research articles: analysis of rhetorical categories for pedagogical purposes. Engl Specif Purposes 1999; 18: 347-66.

[6] Lim JMH. Reporting results in management journal articles: Implications of a genre-based study for literacy development. In: Pandian A, Chakravarthy G, Kell P, Kaur S, Eds. Strategies and practices for improving learning and literacy Serdang: Universiti Putra Malaysia Press 2005; pp. 20-31.

[7] Hopkins A, Dudley-Evans T. A genre-based investigation of the discussion sections in articles and dissertations. Engl Specif Purposes 1988; 7: 113-21.

[8] Holmes R. Genre analysis, and the social sciences: an investigation of the structure of research article discussion sections in three disciplines. Engl Specif Purposes 1997; 16: 321-37.

[9] Weissberg R, Buker S. Writing up Research. Englewood Cliffs, NJ: Prentice Hall 1990.
[10] Nwogu KN. The medical research paper: Structure and functions. Engl Specif Purposes 1997; 16: 119-38.

[11] Posteguillo S. The schematic structure of computer science research articles. Engl Specif Purposes 1999; 18: 139-60.

[12] Gay LR, Mills GE, Airasian P. Educational research: Competencies for analysis and applications, $9^{\text {th }}$ ed. London: Pearson Education Ltd 2009.

[13] Mauranen A. Cultural differences in academic Rhetoric. Frankfurt am Main: Peter Langu 1993.

[14] Connor U, Davis K, de Rycker T. Correctness and clarity in applying for overseas jobs: a cross-cultural analysis of U.S. and Flemish applications. Text 1995; 15: 457-75.

[15] Connor U, Mauranen A. Linguistic analysis of grant proposals Engl Specif Purposes 1999; 18: 47-62.

[16] Norušis MJ. SPSS 16.0 guide to data analysis. Chicago: Pearson Prentice Hall 2008.

[17] Carver RH, Nash G. Doing data analysis with SPSS Version 16. Belmont: Cengage Learning 2009.

[18] Creswell JW. Educational research: Planning, conducting, and evaluating quantitative and qualitative research. Singapore: Pearson Prentice Hall 2008.

[19] Muijs D. Doing quantitative research in education with SPSS London: Sage Publications 2004.

[20] Quirk R, Greenbaum S, Leech G, Svartvik J. A Comprehensive Grammar of the English Language. London: Longman Group Limited 1985. 
[21] Greenbaum S, Quirk R. A student's grammar of the English language. Harlow, Essex: Pearson Education Limited 1992.

[22] Lim JMH. Method sections of management research articles: A pedagogically motivated qualitative study. Engl Specif Purposes 2006; 25: 282-309.

[23] Lim JMH. 'Recommending further research': A pedagogically motivated analysis of linguistic mechanisms and rhetorical functions. In: Wilkinson R, Zegers V, Eds. Researching content and language integration. Maastricht: Maastricht University Language Centre 2007; pp. 137-157.

[24] Lim JMH. Indicating significance of current research: Pedagogical implications of a genre analysis for dissertation writing. Open Appl Linguist J 2008; 1: 46-55.

[25] Kanoksilapatham B. Rhetorical structure of biochemistry research articles. Engl Specif Purposes 2005; 24(3); 269-92.

(C) Jason Miin-Hwa Lim; Licensee Bentham Open.

This is an open access article licensed under the terms of the Creative Commons Attribution Non-Commercial License (http://creativecommons.org/licenses/by-nc/3.0/) which permits unrestricted, non-commercial use, distribution and reproduction in any medium, provided the work is properly cited. 